\title{
Simulating both aerial microclimate and soil temperature from observations above the foliar canopy
}

\author{
Jan Goudriaan and Paul E. Waggoner ${ }^{1}$ \\ Department of Theoretical Production Ecology, Agricultural University, Wageningen, \\ the Netherlands
}

Received: 11 February 1972

\section{Summary}

A simulation model is described for the daily course of microclimatic characteristics of foliar canopy and and the soil underneath. The independent driving forces are the meteorological observations above the canopy. The canopy is described by its geometrical, optical and physiological properties, the soil by its thermal and hydraulic properties.

Comparison with real data shows a good agreement for crop transpiration, soil evaporation and soil heat flux, and to a lesser degree for air temperature and humidity and leaf temperature.

The simulations, covering a full day, were executed with a stratified model. The effect of stratification was investigated by a comparison with a model continuous in height.

\section{Introduction}

The function of a canopy of leaves and of its microbial and insect enemies varies with the temperature and moisture condition of the leaves, some warm and dry in the sun and some cool and moist in the shade. Further, the important transpiration of water from the leaves varies with leaf temperature and with the vapour pressure of the air, which may be considerably moister within the canopy than above. Down in the soil the activity of roots and their pests varies with soil temperature which may fluctuate violently near the surface while it is scarcely changing $30 \mathrm{~cm}$ below. Temperatures and humidities are rarely observed, however, anywhere but in the free air above the canopy. Practically, therefore, if the operating conditions of vegetation and its pests are to be known, they must be calculated from the weather above the foliage, and in this paper we report a method for that calculation.

Parts of the method were already available when we began. That is, the canopy microclimate could be calculated if the temperature and humidity near the soil were known. Similarly, the changes in soil temperature and humidity could be calculated if the temperature and humidity at the surface were known. Our task was joining these two methods.

The method for calculating the canopy microclimate pertains to a steady state. The temperature of the leaves, the temperature and humidity of the air within the canopy,

1 Present address: Connecticut Agricultural Experiment Station, New Haven, Conn., USA. 
and the exchange of energy and water can be calculated from a specification of the canopy, the macroclimate above the canopy, and either 1) the flux of energy from the soil beneath the canopy (Philip, 1964) or 2) the temperature and humidity beneath the canopy (Waggoner et al., 1969). Since the heat capacity of the canopy is relatively small, it is nearly in thermal equilibrium at any moment, and these calculations that pertain to a steady state are reasonable for any moment.

The method for calculating the soil temperature, on the other hanil pertains to the changes in a mass with a large thermal capacity. That is, at any mon ent, the profiles of temperature and water within the soil as well as the surface conditions cause water and heat to move among the soil strata, and this movement is used to produce new profiles that set the stage for fluxes within the soil under the impact of later conditions at the surface. Simulators of this sort for soil temperature and water have been developed by Wierenga and de Wit (1970) and by van Keulen and van Beek (1971).

Thus if temperature and humidity are known at the boundary between soil and air, 1) the instantaneous aerial microclimate and fluxes can be calculated from a description of the canopy and the macroclimate and also 2) the changes in soil temperature and moisture profile can be calculated from the preceding profiles. By macroclimate we mean temperature, humidity, radiation, wind, and diffusivity above the canopy. To remedy the lack of the connecting conditions near the soil we have employed the microclimate simulator to calculate the flux of heat and water from the soil at an instant, employed these fluxes in the soil simulator to change the soil temperature and humidity over the following seconds, and then used the modified soil conditions in a calculation of the microclimate and fluxes at the end of those seconds. Our report, which concerns wholly wet or wholly dry soil surfaces, proceeds in the following fashion. After briefly discussing the factors that affect energy exchange, we present a means of calculating for a steady state both the aerial microclimate within a statified canopy and the fluxes from the soil. The calculation employs the temperature and humidity near the soil. Since this method requires the division of the canopy into strata, it is verified by comparison with a calculation that is essentially continuous in the vertical dimension. In this way a suitable method is obtained for rapidly calculating the flux of energy from the soil at any moment since the canopy has a small thermal capacity and is essential in thermal equilibrium at all times.

Next we present a means of calculating the movement of heat and water within the soil and the changes in soil temperature and water caused by the fluxes from the soil surface calculated by the microclimate simulator. The calculated surface conditions then provide the specification for the next calculation of microclimate and so forth ad infinitum. In the simulator the soil is conceived as composed of strata, and an example shows the effect of this division. A final example shows the realistic simulation of microclimate and soil temperature from macroclimatic observations for two days.

The programming has been in CSMP (Continuous System Modelling Program) for the IBM 360 computer system. It is with slight modifications also available in other machines. Our simulation programmes are available on request in the form of a listing.

\section{The factors that effect energy exchange}

Since the energy exchange will certainly be different in a tall than in a short canopy, or different in a luxuriant than in a sparse canopy, the factors that affect energy exchange amongst the foliage and surrounding air must be obtained before any simulator can 
operate. To provide a specific example we have employed Brown's observations in a maize field on 12 Stptember 1962. The factors that must be obtained are leaf distribution and wetness, radiation and ventilation.

The leaf area was measured by Brown at $0.5-\mathrm{m}$ intervals. The total was $3.73 \mathrm{~m}^{2}$ of foliage per $\mathrm{m}^{2}$ of ground. About $2 \mathrm{~m}^{2}$ were in the first meter above the ground, and the remaining foliage was between 1 and $2.1 \mathrm{~m}$.

The leaf wetne'ss was specified in terms of stomatal resistance given in units of $\mathrm{s} \mathrm{cm}^{-1}$ as is customary in plant physiology. We have calculated the resistance at any height from the absorbed visible radiation at that height and from an observed change in the stomata of maize in another field with changing illumination. These observations by Turner (1970) were summarized by the rule that resistance was $150 \mathrm{~s} \mathrm{~cm}^{-1}$ in the dark, in $30 \mathrm{~W} \mathrm{~m}^{-2}$ light, and 3 in $250 \mathrm{~W} \mathrm{~m}^{-2}$ or brighter; the resistance at intermediate light was interpolated linearly. Influence of water stress on the stomatal resistance has not been taken into account because of abundant rain $(22 \mathrm{~mm})$ two days before. A much more detailed simulation for the stomatal behaviour is given by Penning de Vries (1972); this simulator may be used in further developments.

The energy that the canopy must lose by evaporation and as sensible heat is largely gained by radiation of diverse wavelengths. At several times during the day, therefore, Brown measured the net radiation of all wavelengths. We have employed his observations, estimated a loss of 100 to $40 \mathrm{~W} \mathrm{~m}^{-2}$ during the dark hours, and interpolated linearly between these values for the net gain or loss of radiation above the canopy. Beginning with Monsi and Saeki (1953) several observers have found that radiation within the canopy is extinguished nearly exponentially by foliage. The coefficient varies with wavelength. During the day Brown observed a coefficient of 0.53 per unit of leaf area. No observations were made at night. Since the extinction of long wave radiation is faster than of short-wave radiation, the extinction coefficient was increased from 0.5 during the day to 0.8 during the night. These values for the extinction coefficients agree with theoretical results. A more detailed treatment of the computation of the radiation climate in leaf canopies is given elsewhere (Goudriaan, in prep). Thermal reradiation between the leaves has been neglected. The absorbed net radiation, which must be lost by evaporation and as sensible heat, is calculated as the difference in net radiation between the upper and lower boundaries of a stratum of the canopy.

Visible radiation must also be specified because it contains the wavelengths that affect leaf wetness or stomatal resistance. Since visible radiation or light was not observed, we calculated the light above the canopy as half the incident short-wave radiation measured with a pyroheliometer less a reflection of $8 \%$ of the incident radiation. In the visible region the leaves scatter less than in the near infrared so that the extinction is faster than in the total short-wave region, but slower than for long-wave radiation. A coefficient of 0.7 per unit of leaf area was adopted for the exponential extinction of the visible light. Finally the absorbed visible radiation, which controlled the stomata, was calculated, just like the net radiation, as the disappearance of light in a given stratum divided by the leaf area in that same region.

Ventilation determines the speed with which the water and heat lost by the leaves are carried away, and it is described in terms of the horizontal wind and a coefficient for vertical exchange, the diffusivity. Both of these ventilation parameters were measured above the canopy, and both are assumed liable to an exponential decrease within the crop (Uchijima, 1962). Brown's observations are fit by a coefficient of 2.5 per total height within the crop. As a result wind and diffusivity near the ground are $\mathrm{e}^{-2} .^{3}$ times the value at the top of the canopy. 
At the soil surface, however, a more or less stagnant layer of air will form, impeding the loss of water and heat from the surface. Within this layer the diffusivity will be replaced by the much slower molecular diffusion coefficients. The thickness $\mathrm{L}$ of the layer was calculated as

$$
\mathrm{L}=\frac{1}{0.6} \sqrt{\frac{\mathrm{B} \nu}{\mathrm{u}}}
$$

where $\mathrm{B}$ is the dimension of a clod of soil, $v$ is the kinematic viscosity of air and $\mathrm{u}$ is the windspeed at the soil surface. The factor 0.6 is an empirical constant (McAdams, 1954). We have made $B$ to be $0.05 \mathrm{~m}, \nu$ equals $0.15 \mathrm{~m}^{2} \mathrm{~s}^{-1}$, and $\mathrm{u}$ was calculated as $\mathrm{e}^{-2.5}$ of the wind at the canopy top. The transition between the boundary layer and the turbulent air was assumed to be sudden.

Within the canopy there are also 'laminar' layers formed around the leaves. The thickness of these layers can be calculated with formula 2.1 if we substitute leaf size for $B$ and wind speed at each level for $u$. Moreover, this calculated value of the boundary layer has been divided by 2.5 to account for the extra decrease of the thickness by the turbulence of the canopy air compared to that in wind tunnels where formula 2.1 was developed (Parlange and Waggoner, 1971).

The final factors that affect energy exchange are the temperature and humidity. Brown measured these at canopy top during the day. We have used his observations and estimated that they are $13.5^{\circ} \mathrm{C}$ and $13 \mathrm{mbar}$ at midnight. Calculating these parameters within the canopy is of course the job of the simulator.

\section{Energy exchange within a stratified canopy}

By conceiving the exchange of energy in a canopy of foliage in terms of currents and resistances, one can easily grasp the physical process at work and also understand the rapid, algebraic calculation of fluxes, temperatures and humidities. In Fig. 1 a network of resistors has been superimposed on a background of foliage. A thin surface stratum of soil has also been included. The canopy has been divided into n-2 strata.

In each stratum a flux of $S_{i}$ Watts of radiation are absorbed per $\mathrm{m}^{2}$ of land. $A$ flux of $S_{n-1}$ is absorbed by the ground. The $n$-th stratum, which is below the soil surface, does not absorb any radiation. At steady state the incomes in the canopy must be balanced by the losses of evaporation $V_{i}$ and heat $H_{i}$, while in the ground the currents of $V_{n}$ and $H_{n}$ must be balanced by the current $G$ that warms or cools the soil. Consequently we can write $n$ equations:

$$
\begin{array}{ll}
\mathrm{S}_{\mathrm{i}}=\mathrm{H}_{\mathrm{i}}+\mathrm{V}_{\mathrm{i}} & \mathrm{i}<\mathrm{n} \\
\mathrm{G}=\mathrm{H}_{\mathrm{n}}+\mathrm{V}_{\mathrm{n}} & \mathrm{i}=\mathrm{n}
\end{array}
$$

The losses of sensible heat are apposed by two sorts of registors, $R_{i}$ and $r_{i}$. The $R_{i}$ are the resistances of the bulk air in each stratum, and the first $n-2$ are calculated by integrating the reciprocal of the diffusivity between the centres of the strata. This integration will be examined later in detail. $R_{n-1}$ is a similar integration of diffusivity from the top of the (n-1)th stratum to the soil surface and includes the boundary layer with its molecular diffusivity. Finally $R_{n}$ is half the thickness of the soil stratum (distance from the middle to the surface). divided by its conductivity for heat and multiplied by the 


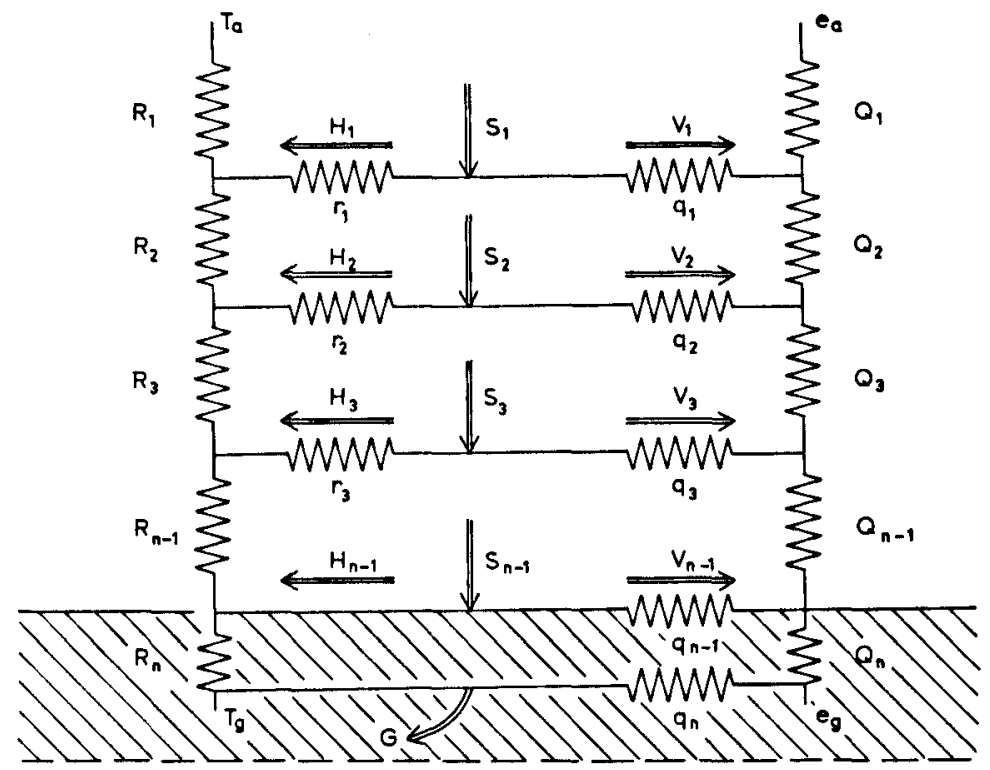

Fig. 1. The conception of the exchange of absorbed radiation $S_{i}$ as sensible heat $H_{i}$, latent heat $V_{i}$ and storage $G$ in the ground. The canopy of leaves is divided into $n-1$ strata. The resistances in $s \mathbf{m}^{-1}$ are caused by the resistance of the soil or air within the canopy to sensible heat transport $R_{i}$, or latent heat transport $Q_{i}$, the boundary layers round the leaves $r_{i}$ or by the boundary layers plus leaf epidermis $q_{i}$.

volumetric heat capacity of the air $\mathrm{C}_{\mathrm{m}}$. This must be done because temperature times $\mathrm{C}_{\mathrm{a}}$ is the driving force (formula 3.3).

The $r_{i}$ are the resistances of the boundary layers around the individual leaves. Each is calculated by dividing the thickness of the boundary layer, which has been calculated for the stratum from leaf dimension and wind speed, by the diffusion coefficient for heat in still air, and by the leaf area in the stratum. In the two lower strata the $R_{i}$ include all the resistance, and $r_{n}$ and $r_{n-1}$ are zero.

Since the resistors have been conceived as the proportionality coefficients between temperature differences and fluxes we can write $2 \mathrm{n}$ equations:

$$
\begin{array}{ll}
\mathrm{C}_{\mathrm{a}}\left(\Theta_{\mathrm{i}}-\mathrm{T}_{\mathrm{i}}\right)=\mathrm{r}_{\mathrm{i}} \mathrm{H}_{\mathrm{i}} & 1 \leqslant \mathrm{i} \leqslant \mathrm{n} \\
\mathrm{C}_{\mathrm{a}}\left(\mathrm{T}_{\mathrm{i}}-\mathrm{T}_{\mathrm{i}-1}\right)=\mathrm{R}_{\mathrm{i}} \sum_{\mathrm{j}=\mathrm{i}}^{n} \mathrm{H}_{\mathrm{j}} & \mathrm{i}>1 \\
\mathrm{C}_{\mathrm{a}}\left(\mathrm{T}_{\mathrm{i}}-\mathrm{T}_{\mathrm{a}}\right)=\mathrm{R}_{1} \sum_{\mathrm{j}=1}^{\mathrm{n}} \mathrm{H}_{\mathrm{j}} & \mathrm{i}=1
\end{array}
$$

$\mathrm{C}_{2}$ is the volumetric heat capacity of the air $\left(1200 \mathrm{~J} \mathrm{~m}^{-3} \mathrm{C}^{-1}\right), \Theta$ is the foliage temperature or soil surface temperature, $T_{2}$ is the temperature of the air above. $\Theta_{n}$ is the temperature of the ground in the middle of the soil stratum, which is equal to $T_{n}$ since $\mathbf{r}_{\mathbf{n}}$ is zero.

The losses of energy by transpiration are also opposed by two sorts of resistors, $Q_{i}$ 
and $q_{i}$. The $Q_{i}$ are the resistances of the bulk air, and the first $n-2$ are equal to $R_{i}$. The resistance $Q_{n-1}$ of the stratum just above the soil surface is calculated as $R_{n-1}$ except the diffusion coefficient for water vapour in air is used rather than for heat. $Q_{n}$ is made very large to precent any noticeable evaporation from the centre of the soil stratum to the surface, so that all evaporation takes place from the surface.

In the canopy the $q_{i}$ are the resistances of the boundary layers around the leaves plus the stomatal resistances. $\mathbf{A} \mathrm{q}_{i}$ is calculated by dividing the stomatal resistance for a unit of leaf area by the leaf area of a stratum and adding this quantity to the corresponding $r_{i}$. The $q_{a}$ of the soil is made very large, just like $Q_{n}$. Since $22 \mathrm{~mm}$ of rain had fallen on Brown's corn only two days before his observations, we considered the soil in that example to be wet. To perform this we made $q_{n-1}$ zero. If we were to simulate with a dry soil surface, $\mathbf{q}_{\mathrm{n}-1}$ would be very large.

The proportionalities between fluxes of vapour and the differences in vapour pressures allow us to write $2 \mathrm{n}$ equations:

$$
\begin{array}{ll}
\frac{\mathrm{C}}{\gamma} \mathrm{a}\left(\varepsilon_{\mathrm{i}}-\mathrm{e}_{\mathrm{i}}\right)=\mathrm{q}_{\mathrm{i}} \mathrm{V}_{\mathrm{i}} & 1 \leqslant \mathrm{i} \leqslant \mathrm{n} \\
\frac{\mathrm{C}}{\gamma} \mathrm{a}\left(\mathrm{e}_{\mathrm{i}}-\mathrm{e}_{\mathrm{i}-1}\right)=\mathrm{Q}_{\mathrm{i}} \sum_{\mathrm{j}=\mathrm{i}}^{\mathrm{n}} \mathrm{V}_{\mathrm{i}} & \mathrm{i}>1 \\
\frac{\mathrm{C}}{\gamma} \mathrm{a}\left(\epsilon_{1}-\mathrm{r}_{\mathrm{a}}\right)=\mathrm{Q}_{1} \sum_{\mathrm{i}=1}^{\mathrm{n}} \mathrm{V}_{\mathrm{i}} & \mathrm{i}=1
\end{array}
$$

$e_{a}$ is the vapour pressure of the air above, $\varepsilon_{i}$ is the vapour pressure inside the leaf, and $\gamma$ is the psychrometric constant $\left(0.67 \mathrm{mbar} \mathrm{C}^{-1}\right)$. Since we have assumed for both ground and leaf that the vapour is saturated, we can write in equations

$$
\varepsilon_{\mathrm{i}}=\mathrm{e}_{\mathrm{sa}}+\triangle\left(\Theta_{\mathrm{i}}-\mathrm{T}_{\mathrm{a}}\right) \quad 1 \leqslant \mathrm{i} \leqslant \mathrm{n}
$$

where $e_{s a}$ is the saturated vapour pressure at temperature $T_{a}$ of the air above and $\triangle$ is the slope of the relation between saturation vapour pressure and temperature.

Six times $n$ linear equations have now been derived from Fig. 1, specifying how the radiant energy $S_{i}$ warms the foliage and causes the exchange of that energy as sensible heat that warms the air, as evaporation that moistens the air or as energy that warms the ground. These $6 n$ equations can be solved for $6 n$ unknowns: $n_{i}, n V_{i}, n T_{i}, n e_{i}$ $\mathrm{n} \varepsilon_{\mathrm{i}},(\mathrm{n}-1) \Theta_{\mathrm{i}}$ and $\mathrm{G}$. The algebraic solution has already been presented by Waggoner et.al. (1969) and is not duplicated here.

The conception of Fig. 1 also specifies the way that microclimatic temperatures and humidities of the air within the canopy are created. The upward fluxes of heat and vapour cause the temperature and humidity to change from those within the soil according to the resistances and the fluxes of heat and vapour that are recruited from each stratum that is passed through. Since the thickness of the strata cannot be neglected, we must now ask where the contributing flux $\mathrm{H}_{\mathrm{i}}$ or $\mathrm{V}_{\mathrm{i}}$ should be injected into the turbulent air. From a comparison with the results of the continuous model, to be explained later, it appeared that injection in the middle of the canopy strata is to be preferred, except on layer n-1 where the absorption of the radiation occurs on the soil surface, and thus on the bottom of the stratum. Consequently the simulated temperatures and humidities will also be located in the centres of the strata. 
Now we shall justify the integration of the diffusivities $\left(D_{i} m^{2} s^{-1}\right)$ to obtain $R_{i}$ and $Q_{i}$. First, equation (3.3) can be written as

$$
\Phi=\mathrm{C}_{\mathrm{a}}\left(\mathrm{T}_{\mathrm{i}}-\mathrm{T}_{\mathrm{i}-1}\right) / \mathrm{R}_{\mathrm{i}}
$$

where $\Phi$ is the sum of the fluxes $H$ for $\mathrm{j}$ from $\mathrm{i}$ to $\mathrm{n}$.

From the definition of diffusivity it follows that also

$$
\Phi=-\mathrm{C}_{\mathrm{a}} \mathrm{D}_{\mathrm{a}} \frac{\mathrm{dT}}{\mathrm{dz}}
$$

If the layers are thin enough, $T_{i}-T_{i-1}$ will about equal $-\Delta z \frac{d T}{d z}$.

Under this assumption it follows from combination of (3.7) and (3.8) that

$$
\mathrm{R}_{\mathrm{i}}=\frac{\Delta \mathrm{z}}{\mathrm{D}_{\mathrm{a}}}
$$

If $\mathrm{D}_{2}$ varies along the distance $\Delta \mathrm{z}$, the resistance must be obtained as

$$
R_{i}=\int_{z_{i-1}}^{z_{i}} \frac{d z}{D_{2}(z)}
$$

where $z_{i-1}$ and $z_{i}$ are the heights of the centres of the two adjacent layers. It is convenient that $D_{a}$ varies exponentially with $\mathrm{z}$ so that this integration can be executed by hand. In the continuous model, which is introduced in the next chapter, this is not a requirement since the continuously varying $D_{a}$ will be used rather than the resistances.

\section{Energy exchange within the continuous model}

In the continuous model, height has not been stratified, but all profiles are continuously calculated with height. Mathematically the continuous model is quite different although it represents the same physical phenomena. Because it basically gives a better representation of het vertical dimension it can be used to test the errors introduced in the stratified model by the stratification itself. Also we can test another shortcoming of the stratified model, namely the linearization of the saturated vapour pressure curve (equation 3.6). In the continuous model the non-linear relation between the saturated vapour and the leaf temperature can be used without mathematical objections.

The continuous model is formulated in terms of differential equations rather than strata. The basis for the derivation of the differential equations is the equation for the flux (3.8):

$$
\Phi=-\mathrm{C}_{\mathrm{a}} \mathrm{D}_{\mathrm{a}} \frac{\mathrm{dT}}{\mathrm{dz}}
$$

or

$$
\frac{\mathrm{dT}}{\mathrm{dz}}=-\frac{\Phi}{\mathrm{D}_{\mathrm{a}} \mathrm{C}_{\mathrm{a}}}
$$


To enable elimination of $\Phi$ this equation must be differentiated with respect to $\mathrm{z}$ :

$$
\frac{\mathrm{d}^{2} \mathrm{~T}}{\mathrm{dz}^{2}}=-\frac{\frac{\mathrm{d} \Phi}{\mathrm{dz}}}{\mathrm{D}_{\mathrm{a}} \mathrm{C}_{2}}+\frac{\Phi \frac{\mathrm{dD}_{\mathrm{a}}}{\mathrm{dz}}}{\mathrm{D}_{\mathrm{a}}{ }^{2} \mathrm{C}_{2}}
$$

The flux $\Phi$ in the second term can easily be substituted by the expression in 3.8 so that we get:

$$
\frac{\mathrm{d}^{2} \mathrm{~T}}{\mathrm{dz}^{2}}=-\frac{\frac{\mathrm{d} \Phi}{\mathrm{dz}}}{\mathrm{D}_{\mathrm{a}} \mathrm{C}_{\mathrm{a}}}-\frac{\frac{\mathrm{dT}}{\mathrm{dz}} \frac{\mathrm{d} \mathrm{D}_{\mathrm{a}}}{\mathrm{dz}}}{\mathrm{D}_{\mathrm{a}}}
$$

The first derivative of the flux with respect to height, the source strength in fact, is found as the product of the foliar density $F\left(\mathrm{~m}^{2}\right.$ foliage $/ \mathrm{m}^{3}$ air) and the sensible heat loss per leaf area. $\mathrm{F}$ is a function of height and is one of the data describing the canopy. The sensible heat loss per leaf area and similarly the latent heat loss per leaf area can be found from the leaf energy balance because they add up to the absorbed radiation per leaf area. Since we assumed an exponential extinction of net radiation with leaf area, the absorbed total radiation per leaf area can be found as the first derivative of the exponential profile with respect to leaf area. The energy balance of the leaves requires that

$$
\mathrm{h}+\mathrm{v}=\mathrm{s}
$$

where $h$ is the sensible heat loss per leaf area, $v$ the latent heat loss and $s$ the absorbed total radiation. The distribution between $\mathrm{h}$ and $\mathrm{v}$ is governed by the temperature $\mathrm{T}$ and vapour pressure $e$ of the ambient air, and by the resistance $r_{b}$ of the boundary layer and $r_{s}$ of the stomata. These resistances pertain to fluxes per leaf area. In the stratified model $r_{i}$ and $q_{i}$ oppose the fluxes from the strata and are therefore divided by the leaf area in the stratum. Here is no need for the division. The equations for $h$ and $v$ are:

$$
\begin{aligned}
& h=(\Theta-T) C_{a} / r_{b} \\
& v=(\varepsilon-e) C_{a} / \gamma\left(r_{b}+r_{\varepsilon}\right)
\end{aligned}
$$

The relation between $\varepsilon$ and $\Theta$ may be taken as the linear relation of (3.6) or as the more realistic curved relationship of the saturated vapour pressure with temperature. The four equations $4.4,4.5,4.6$, and the saturated vapour pressure equation can be solved simultaneously by means of a CSMP feature, the 'implicit loop'. Besides $h$ and $v$ we also get the leaf temperature $\Theta$. Now when we have found $h$ and $v$, we can rewrite 4.3 substituting $\frac{\mathrm{d} \Phi}{\mathrm{dz}}$ :

$\frac{d^{2} T}{d^{2}}=-\frac{h F}{D_{a} C_{a}}-\frac{\frac{d T}{d z} \frac{d D_{a}}{d z}}{D_{a}}$

In the same way a similar equation for the vapour pressure can be derived:

$\frac{\mathrm{d}^{2} \mathrm{e}}{\mathrm{dz} \mathrm{z}^{2}}=-\frac{v \mathrm{~F}_{\gamma}}{\mathrm{D}_{\mathrm{a}} \mathrm{C}_{\mathrm{a}}}-\frac{\frac{\mathrm{de}}{\mathrm{dz}} \frac{\mathrm{dD}_{\mathrm{a}}}{\mathrm{dz}}}{\mathrm{D}_{\mathrm{a}}}$ 
Both the temperature and the vapour pressure in the air can be found by a simultaneous integration of these equations, while the leaf temperature profile is found as a byproduct. Integration has been performed by the language CSMP with the height $\mathrm{z}$ as the continuous variable.

The integration starts at the top of the boundary layer on the soil surface. Because of the completely different diffusivity of the boundary layer it was chosen as a separate stratum between the stratified soil and the continuous canopy section. In Fig. 2 a scheme has been drawn of the resistances and fluxes near the soil surface. Because we assume a wet surface, the vapour pressure $e_{s}$ will equal the saturated vapour pressure at temperature $T_{s}$. Knowing $T_{g}$, the temperature of the first soil stratum, and the temperature $T_{b}$ and vapour pressure $e_{b}$ on top of the boundary layer the fluxes $H$ and $V$ and temperature $T_{3}$ can be calculated in a way similar to the solving of the leaf energy balance. The diffusivity on top of the boundary layer is found with our rule of exponential extinction with height of the turbulent diffusivity. The gradients then follow according to equation 4.1 from the fluxes $H$ and $V . T_{b}$ and $e_{b}$ are one pair of the initial conditions required for the integration of the first derivatives and $\left(\frac{d T}{d z}\right)_{b}$ and $\left(\frac{d e}{d z}\right)_{b}$, the other for the integration of the second derivatives. By the choice of $T_{b}$ and $e_{b}$ the initial conditions are fixed. They should be such that after integration to the top the calculated air temperature and vapour pressure equal the observations. Therefore $T_{b}$ and $c_{b}$ must be guessed, integration executed, and the outcome must be checked. The

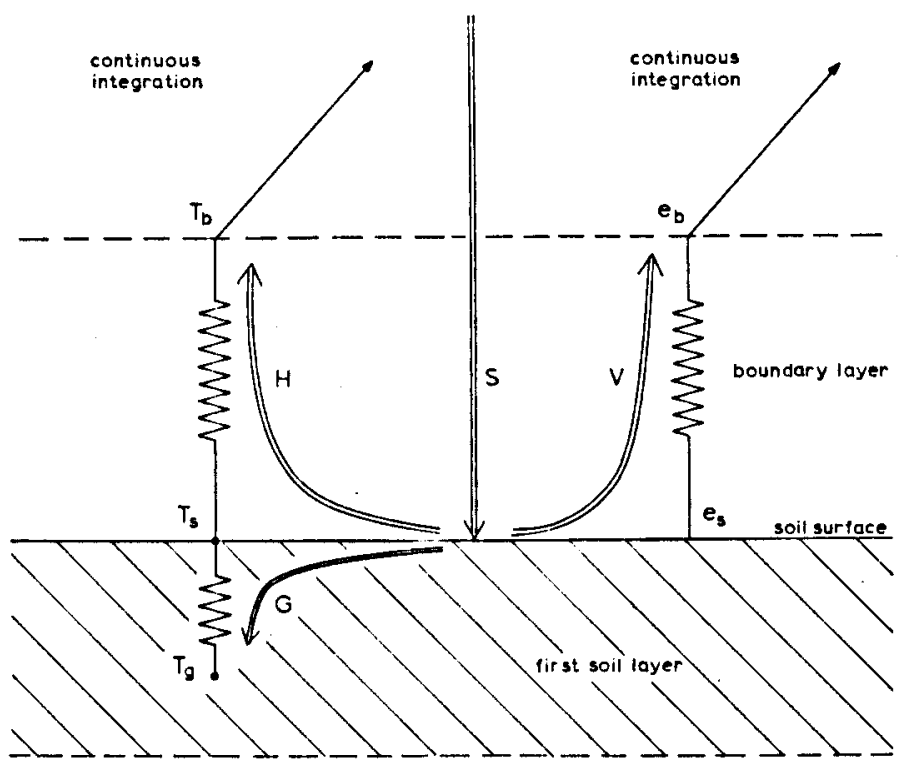

Fig. 2. Scheme of resistances and fluxes at the soil surface in the continuous model. The resistances of the boundary layer for sensible heat $(H)$ and for latent heat $(V)$ are calculated from the molecular diffusion coefficients. The net radiation $S$ is absorbed by the soil surface, from where also the evaporation takes place. The soil heat flux $G$ flows through the resistance formed by half of the first soil to its centre. 
errors at the top provide the information for a second guess, integration follows and so forth. When in the end the right values for $T_{b}$ and $e_{b}$ are found, the energy balance of the soil surface is the right one, and we also find the soil heat flux $G$ that warms the soil.

The necessary integrations cause lengthy calculation and will not permit the calculation during several days required to demonstrate the realism of the joint aerial microclimate and soil temperature model. The continuous model does, however, provide at one moment a standard for measuring the errors introduced by the swifter calculation of the stratified model. In this respect it has been useful in showing that the injection of the fluxes in the stratified should be in the middle of the strata rather than at the bottom.

\section{Comparison of the stratified to the continuous model}

The costs of calculation by the slow continuous model are prohibitive for a full day of simulation. Therefore the comparison must be limited to for instance midnight and noon. The features to be compared are the effect of the stratification itself, het effect of the place of injecting the fluxes into the turbulent air, and also the effect of linerization of the saturated vapour pressure curve (3.6), which is a requirement for the stratified model because of its linear algebra.

The influence of the linearization can be tested with the continuous model itself. One run is made with the straight vapour pressure relation, which has the reference point at air temperature, and one with the real curvilinear relation. Only one test was made, at noon, and the effect appeared to be entirely negligible. For the leaf temperatures the difference was never more than $0.01^{\circ} \mathrm{C}$ and for the air temperatures even less. The transpiration from the canopy was changed $1 \%$. From this we concluded that linearization in the stratified model does not introduce serious errors.

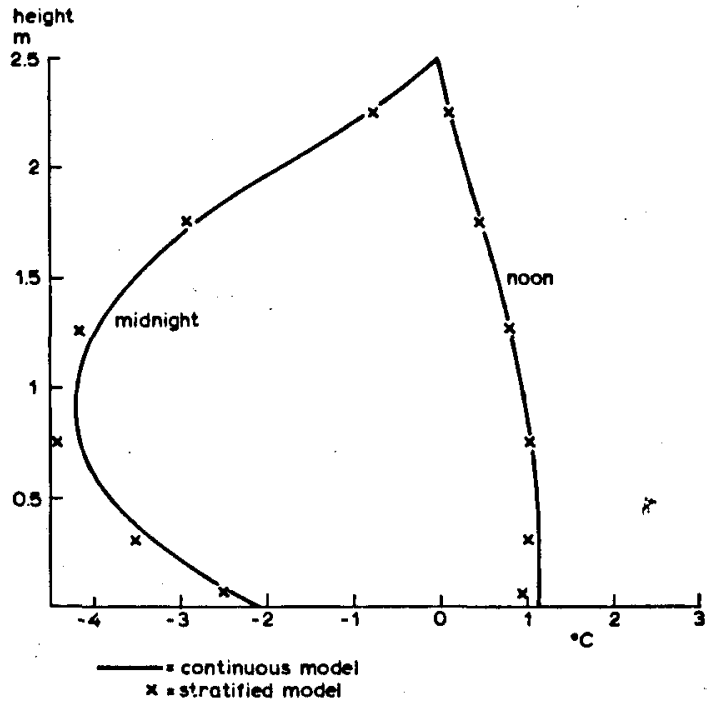

Neth. J. agric, Sci. 20 (1972)
Fig. 3. Comparison between the continuous and the stratified model for midnight and for noon. The simulated air temperature is plotted relative to the temperature at the top. 
Table 1. Comparison of some fluxes calculated by the continuous and by the stratified model at midnight and at noon, in $\mathrm{J} \mathrm{m}^{-2} \mathrm{~s}^{-1}$.

\begin{tabular}{|c|c|c|c|c|c|c|}
\hline \multirow{3}{*}{\multicolumn{2}{|c|}{$\mathrm{G}$}} & \multirow{3}{*}{$\begin{array}{c}\text { Noon } \\
\text { continuous } \\
43.3\end{array}$} & \multicolumn{2}{|l|}{ ' } & \multicolumn{2}{|l|}{ Midnight } \\
\hline & & & stratified & & continuous & stratified \\
\hline & & & 43.4 & $\therefore$ & -16.5 & -17.1 \\
\hline Evaporation from & soil & 81.8 & 80.2 & & 8.0 & 8.4 \\
\hline Sensible heat loss & from soil & -18.7 & -17.2 & . & . 5.0 & 5.3 \\
\hline Total evaporation & and transpiration & 357 & 371 & & -18.7 & -19.9 \\
\hline Total heat loss & & 293 & 273 & & -35.8 & -33.1 \\
\hline Net radiation & $i$ & 687 & 687 & & -70.1 & -70.1 \\
\hline
\end{tabular}

The influence of the stratification itself is shown in Fig. 3a and 3b. Here the fluxes are injected in the centre of the strata, which gave markedly better agreement than injection at the bottom. To prevent loss of simplicity no further refinement in the right place has been attempted. Any necessary improvement from here on should be obtained by increasing the number of strata. The profiles of the air temperature and the vapour pressure are presented for midnight and noon. The deviation is never larger than $0.2^{\circ} \mathrm{C}$ and 0.2 mbar. The fluxes are compared in Table 1.

Adding the fluxes shows that the energy balance of the whole system in the case of the continuous model is in error by $6 \mathrm{~J} \mathrm{~m}^{-2} \mathrm{~s}^{-1}$ at midnight. Since this is impossible according to the employed mathematics, the reason must be the accumulation of truncation errors during integration the more likely because it is a double integration of second order differential equations (4.7 and 4.8). This suspicion is confirmed by the fact that widening the error criterion for the step of integration increases the error in the energy balance. These considerations have only a theoretical meaning and no influence on the results because the deviation is less than $1 \%$.

Since there is no large difference in temperatures and humidities, and the fluxes especially at the soil surface, are scarcely affected, the distortion by the stratification is not large and quite acceptable. Taking into considering that the continuous model requires fully 45 times as long computation time as required for the stratified model, we accepted the small difference and decided in favour of the stratified model as our working model.

\section{Energy and water movement in a stratified soil}

From the point of simulation in time, and also the method of calculation, the soil portion of the simulator is the main program, calling upon the aerial subprogram for the heat and water fluxes at the soil surface at each time interval and then employing these to advance to a later time.

For simulation the essential difference between the canopy and soil is the negligible heat capacity of the foliage and the big heat capacity of the soil. The canopy is, therefore, essentially at a steady state at each instant and the aerial portion of the simulator can provide the fluxes for the soil portion of the simulator. Since the steady state need be valid only for the heat content of the leaves, it is not necessary that the stomata be in equilibrium. At the same time the temperature and water content of the soil are only slightly changed by these fluxes from the soil surface, and the simulator can provide 
the temperature and humidity at the lower boundary of the aerial simulator.

The movement of water within the soil that is caused by evaporation from the soil is also simulated, the method resembles that developed by Wierenga and de Wit (1970) and van Keulen and van Beek (1971). The scope of our soil simulation is limited, of course, by our neglect of the removal of water by roots and the restriction to wholly wet of wholly dry surfaces. Nevertheless, the simulation of soil water movement does permit us to see that a disturbing dry layer of soil likely does not form on the wet soil during the two days that we shall eventually simulate. In other words, the diffusivity for water in the soil was apparently large enough that the capillary rise water kept the surface wet.

The soil temperature $T$ must satisfy the differential equation

$$
\frac{\mathrm{dT}}{\mathrm{dt}}=\frac{1}{\mathrm{C}_{\mathrm{s}}} \frac{\mathrm{d}}{\mathrm{dz}}\left(\lambda \frac{\mathrm{dT}}{\mathrm{dz}}\right)
$$

where $\lambda$ is the conductivity $\left(\mathrm{W} \mathrm{m}^{-1} \mathrm{C}^{-1}\right)$ and $\mathrm{C}$ the heat capacity $\left(\mathrm{J} \mathrm{m}^{-3} \mathrm{C}^{-1}\right) . \mathrm{C}$ was calculated from the volumetric water content $X_{w}$ and solid content $X_{s}$ by the following equation given by de Vries on page 211 in van Wijk (1963):

$$
\mathrm{C}_{\mathrm{s}}=4.18 \times 10^{3} \mathrm{X}_{\mathrm{w}}+1.60 \times 10^{6} \mathrm{X}_{\mathrm{s}}
$$

De Vries also gives a method for calculating the conductivity. Because this is an involved method and because we knew that the soil would be wet, we always used an average value for wet soil. We set $\lambda$ equal to $1.3 \mathrm{~J} \cdot \mathrm{m}^{-1} \mathrm{C}^{-1}$.

To solve equation 6.1 the soil was divided into 25 layers. The integration in time was by intervals of 360 seconds when the uppermost stratum was $2 \mathrm{~cm}$ thick and intervals of 4 seconds when it was $2 \mathrm{~mm}$ thick. The thickness of the second stratum was made 1.2 times the first, the third was made 1.2 times the second, and so forth. When the thickness of the first layer was $2 \mathrm{~cm}$, the 25 layers had a total thickness of $9.4 \mathrm{~m}$. The thickness of the upper most stratum being the thinnest determined the interval of calculation that could be taken, the permissible time interval increasing with the square of the thickness. After the simulator has been fully introduced, we shall examine this matter of thickness further.

At the beginning of the calculation at midnight, all strata were assigned a uniform temperature of $14.5^{\circ} \mathrm{C}$, about the average daily temperature. The downward movement of heat into the uppermost stratum was the $G$ calculated by the aerial subprogram. The flux of heat through the other boundaries of the strata were then calculated from the product of $\lambda$ and the difference in temperature between the adjacent strata divided by the distance between their centres. The new heat content of each stratum was then obtained by adding the net flux hrough its two boundaries times the time interval to its initial heat content. Finally the new temperatures of the strata were calculated by dividing their new heat contents by their volumes and heat capacities.

The change in the volumetric water content $X_{w}$ of the soil was calculated similarly with the equation

$$
\frac{\mathrm{dX}_{\mathrm{w}}}{\mathrm{dt}}=\frac{\mathrm{d}}{\mathrm{dz}}\left(\mathrm{D}_{\mathrm{s}} \frac{\mathrm{dX} \mathrm{w}}{\mathrm{dz}} \mathrm{w}-\mathrm{K}\right)
$$

where $D_{s}$ is the diffusivity for water in soil $\left(\mathrm{m}^{2} \mathrm{~s}^{-1}\right)$, and $K$ is the hydraulic conductivity of the soil $\left(\mathrm{m} \mathrm{s}^{-1}\right) . \mathrm{D}_{\mathrm{s}}$ is a function of the water content, and its was obtained by interpolation from a table. The range of the table was from $X_{w}$ at 0.04 with $D$ at $5.10^{-3}$ $\mathrm{m}^{2} \mathrm{~s}^{-1}$ to $\mathrm{X}_{\mathrm{w}}$ at 0.44 and $\mathrm{D}$ at $0.3310^{-3} \mathrm{~m}^{2} \mathrm{~s}^{-1}$. Similarly $\mathrm{K}$ was varied from $5.10^{-14}$ 
$\mathrm{m} \mathrm{s}^{-1}$ to $1.510^{-8}$ over te same range of $\mathrm{X}_{\mathrm{w}}$. The tables for $\mathrm{D}$ and $\mathrm{K}$ were given for Gilat loamby Bresler et al. (1970). The stratification of the soil and the time intervals for the approximate integration were, of course, the same as for obtaining the temperature.

At the beginning of the calculation all strata were assigned a uniform water content of 0.2. The upward loss of water from the uppermost stratum was the $V_{n-1}$ calculated by the aerial subprogram after conversion from energy flux to water flux. The remaining steps in the calculation of the new water contents were then similar to the calculation of the new temperatures for the 25 strata.

Now we must return to the matter of the interval of approximate integration over time and depth. On the one hand, the interval must be sufficiently long to calculate three days of change at an acceptable cost for computation. On the other hand, a long computation interval requires thick soil strata to avoid oscillations of the simulated water and heat contents of the strata. The thickness of the soil strata is limited by the gradients, because heat water content are made uniform within a stratum.

The effect of the thickness of the surface stratum was explored by comparing the evaporation from the soil surface and the flux of heat. $G$ into the surface stratum when it was $2 \mathrm{~mm}$ versus $2 \mathrm{~cm}$ thick. The initial soil temperature profile used in the simulation can exaggerate the difference caused by the two thicknesses. If an abnormal, uniform soil temperature profile is used to begin the simulation, the surface stratum will initially exchange heat only from its upper surface, causing an unrealistically steep temperature profile in the upper soil. To avoid this exaggeration, calculation was begun from a more normal temperature profile, which was created by simulation from midnight to noon with a $2 \mathrm{~cm}$ stratum and the joint aerial and soil simulator. The initial temperatures of the thinner strata were, of course, interpolated from the thicker ones of this preliminary simulation. The comparison of the $2 \mathrm{~cm}$ and $2 \mathrm{~mm}$ strata, with lower strata which are the multiples of the surface layers, can now be presented. The comparison was made for a midday hour when differences should be greatest (Fig. 4). The difference in evaporation between the $2-\mathrm{cm}$ and $2-\mathrm{mm}$ strata was never larger than $1.1 \mathrm{~W} \mathrm{~m}^{-2}$, which is

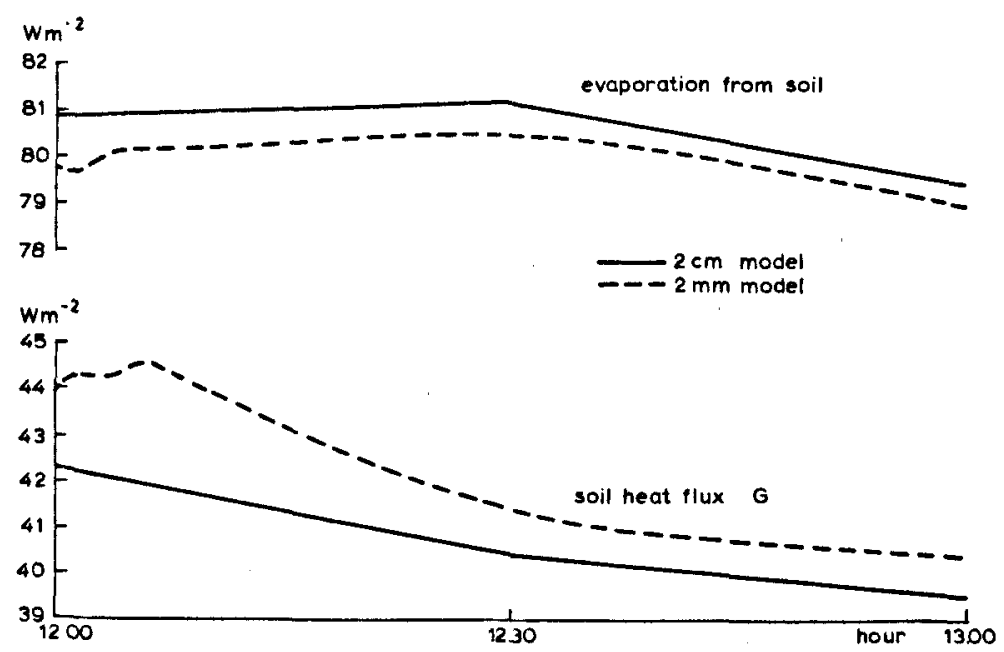

Fig 4. Effect of the thickness of the soil strata in a one hour simulation. 
small compared to a value of $81 \mathrm{~W} \mathrm{~m}^{-2}$. The deviation of the soil flux $\mathrm{G}$ was and had a maximum of $2 \mathrm{~W} \mathrm{~m}^{-2}$ in a value of $41 \mathrm{~W} \mathrm{~m}^{-2}$. This occurred however, 1 beginning when the initialization probably was the reason that the temperature pro did not have a settled shape yet. After half an hour agreement was much better. Fron. this comparison it is abvious that a $2-\mathrm{cm}$ layer gives practically the same result as a $2-\mathrm{mm}$ layer so long as no dry layer is formed on the top of the soil.

When a stratum of $2 \mathrm{~mm}$ was used, water diffused into it from the lower layers rapidly enough to keep the water content of the top layer as high as $19.63 \%$ after one hour when we began with $20 \%$. Consequently, the loss in water was distributed rather evenly over the top 5 to 10 layers. The loss in water from the first layer ( $1 \mathrm{~mm}$ depth) after one hourt was $0.37 \%$, from the fifth (13 mm depth) $0.28 \%$ and from the tenth (47 mm depth) $0.08 \%$. From this it seems justified to average over $2 \mathrm{~cm}$. When a $2 \mathrm{~cm}$ stratum was used, the moisture content of the top layer decreased from 20 tot $19.12 \%$ in 48 hours, of the fifth layer at a depth of $13 \mathrm{~cm}$ from 20 to $19.35 \%$ and of the tenth layer at a depth of $47 \mathrm{~cm}$ only from 20 to $19.88 \%$. For the deeper layers it is not a realistic calculation because the water uptake from the roots has not been taken into account, but it does indicate together with the 2-mm layer simulation that no dry layer formation occurs under these circumstances. This conclusion permits simulation with the $2-\mathrm{cm}$ top stratum.

\section{Joint simulation of aerial microclimate and soil temperature}

At this point it is worthwhile recalling our initial purpose. Since the microclimatic characteristics of foliage and soil underneath are rarely observed, although important, our purpose was composing a simulator that would provide these needed parameters from observations of the macroclimate alone. Some characteristics of the soil and canopy, such as stomatal resistance as a function of absorbed light, must be known as well and are also used as input into the simulator. $A$ full list of input and output parameters is given in the discussion.

The aerial portion of the simulator will calculate the temperatures and humidities above the ground and also the fluxes from canopy and soil. These fluxes will modify the soil, and new conditions near the soil will be provided by the soil portion to the aerial portion of the simulator. Starting from assumed initial profiles of uniform temperature and water content, the simulator will gradually transform the uniform profiles to realistic ones under the impact of the realistic canopy and the macroclimate above. We begin with a wet soil and present some graphs to show that by the second day the entire simulator produced realistic results. The uniform initial temperature was the average daily air temperature of $14.5^{\circ} \mathrm{C}$. If we began with a temperature of $18^{\circ} \mathrm{C}$ instead of $14.5^{\circ} \mathrm{C}$, one day longer was required before the canopy and the upper $50 \mathrm{~cm}$ of soil reached a cyclic equilibrium.

Our standard of realism was Brown's observations in a maize field on 12 September 1962. The ranges of the weather factors above the canopy abstracted from his daytime observations and extrapolated by us into the nighttime are as follows: temperature, 13.5 to $20.6^{\circ} \mathrm{C}$; vapour pressure, 11.2 to $15.0 \mathrm{mbar}$; net all-wave radiation, -100 to $690 \mathrm{~W}$ $\mathrm{m}^{-2}$; visible radiation, 0 to $400 \mathrm{~W} \mathrm{~m}^{-2}$; wind, 0.2 to $3 \mathrm{~m} \mathrm{~s}^{-1}$; diffusivity, 100 to $4720 \mathrm{~cm}^{2}$ $\mathbf{s}^{-1}$. The extinction coefficients for diffusivity and wind within the canopy were a steady 2.5 per canopy height, the coefficient for light was a steady 0.7 per leaf area, and the coefficient for all-wave radiation varied from 0.8 per leaf area when the radiation at 


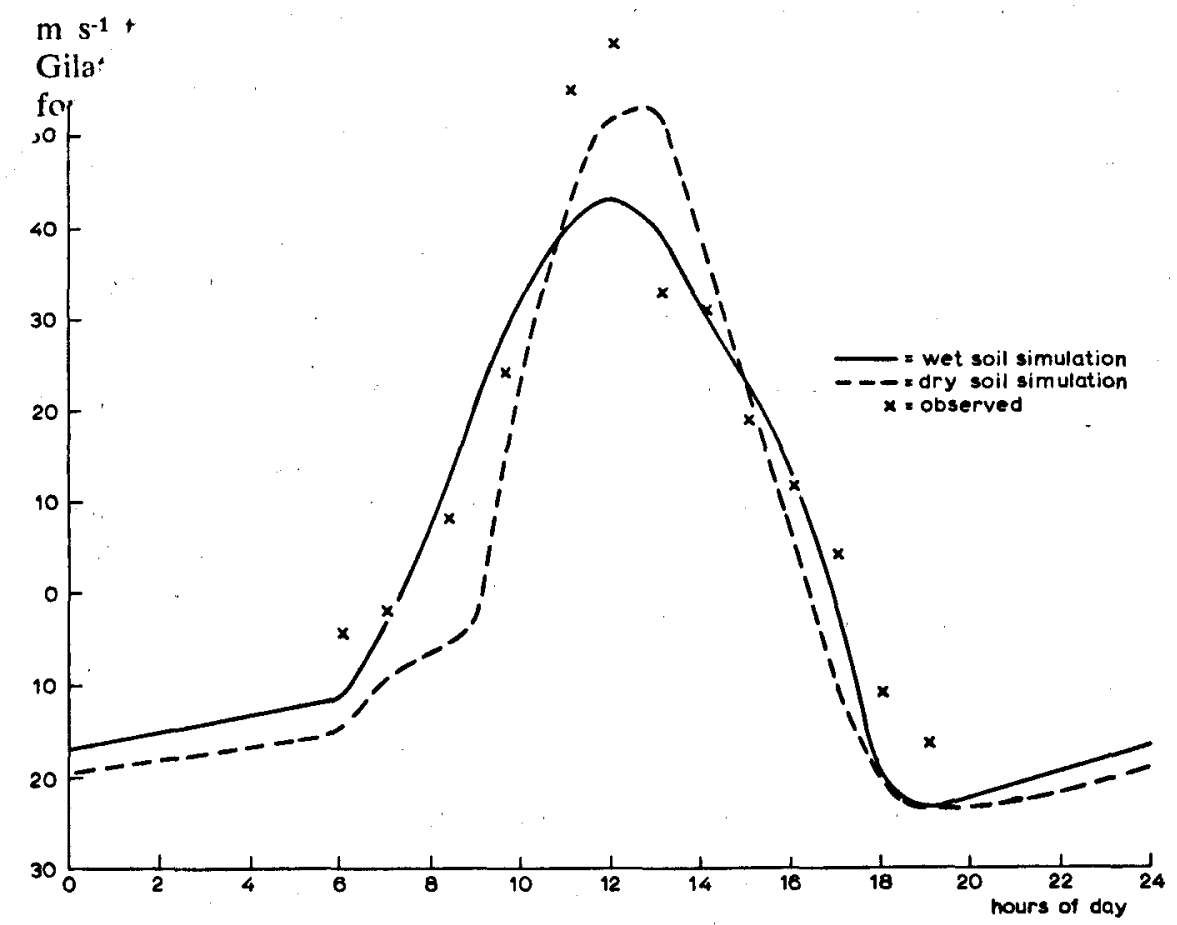

Fif. 5. Simulated and observed soil heat flux. Simulation shows the effect of soil wetness. The high fluxes at noon are due to the N-S orientation of the rows of maize plants.

canopy top was less than $0 . \mathrm{W} \mathrm{m} \mathrm{m}^{-2}$ to 0.5 when the radiation was greater than $100 \mathrm{~W}$ $\mathrm{m}^{-2}$.

Simulation was begun at midnight with uniform initial conditions in the soil. When midnight was reached after 24 hours of calculation the macroclimatic observations were repeated, but in the soil a much more realistic profile had been developed and was, of course, used. The difference between the first and the second day was so small that it would be useless to repeat the calculations for a third day.

Since the flux of heat $G$ into the soil is of primary importance at the junction between the soil and aerial portions of the joint simulator, it is presented first (Fig. 5). The simulated course agrees well with the observed values by Brown, and has a realistic pattern. The noon maximum is about $6 \%$ of the net radiation falling at the canopy to at that time. The large deviations at 12.00 and 11.00 hours from the regular pattern justify the suspicion of some disturbance in the circumstances. The extraordinarily high values of the soil heat flux are caused by the North-South row orientation. Therefore other comparisons will be at 14.00 rather than at 12.00 . The heat flux $G$ being the driving force it is not surprising that the soil temperatures also behave realistically (Fig. 6). Soil temperature was not observed, but a comparison of simulated and experimental soil temperatures was made by Wierenga and de Wit (1970) for another example, which shows about the same pattern. Both the amplitude of the temperature courses and their phases vary at $1 \mathrm{~cm}, 13 \mathrm{~cm}$, and $47 \mathrm{~cm}$ as one expects in a moist, shaded soil. Another test for the program is the evapotranspiration and the soil evaporation. The 


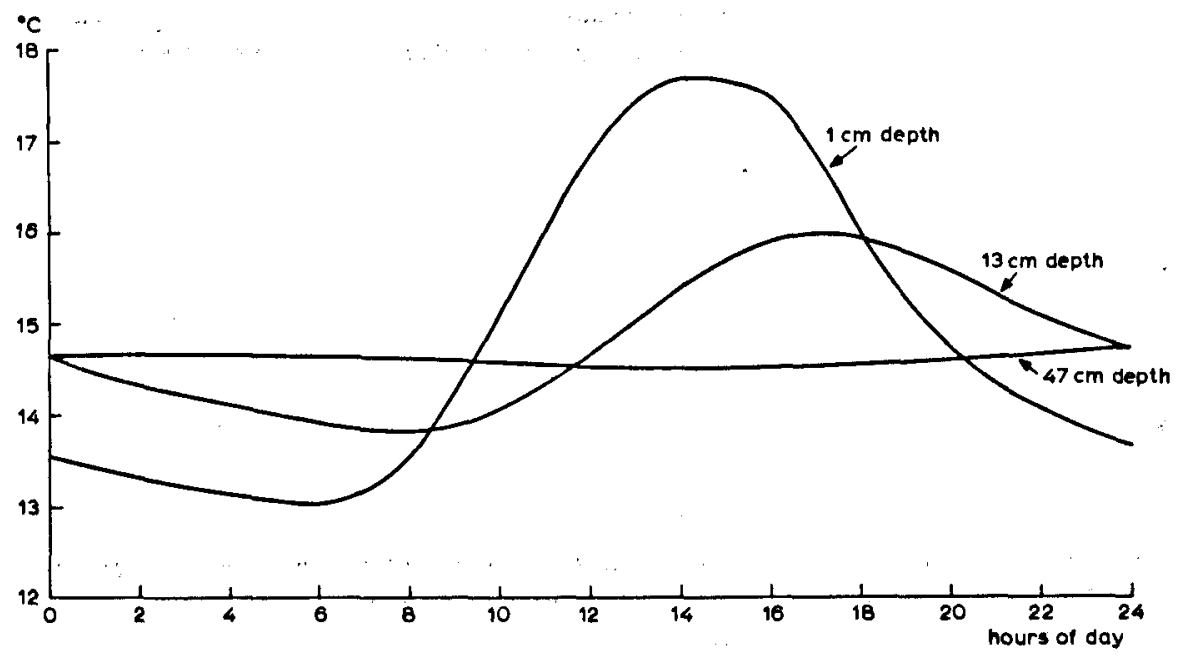

Fig. 6. Simulated daily course of temperatures in the wet soil.

simulated and observed courses are presented in Fig. 7. The agreement of the evapotranspiration is striking if we recall that the stomatal resistance, which profoundly affects the transpiration, has not been adjusted and has been made a single function of light. During the afternoon a slight depression of the observed transpiration can be seen

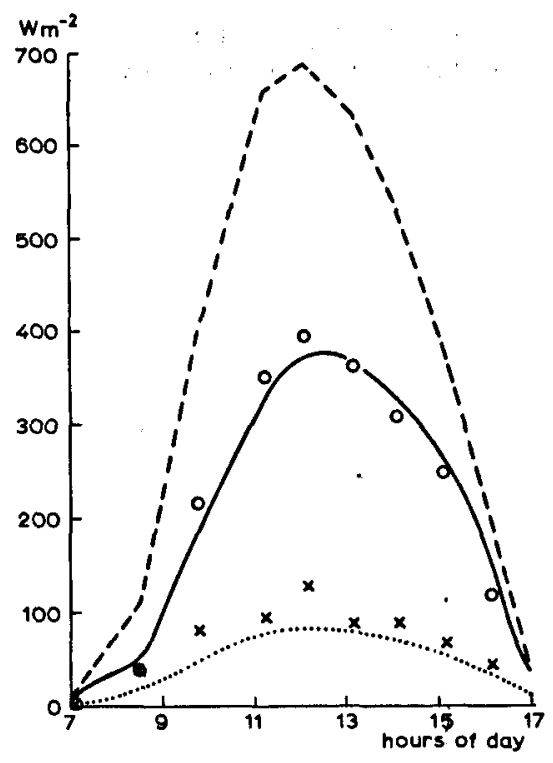

-- measured net radiation used as input s simulated evapotranspiration s simulated soil evaporation

o measured evapotranspiration

$x=$ measured soil evaporation
Fig. 7. Simulated and measured daily course of soil evaporation and total evapotranspiration. The used net radiation is given for comparison. 


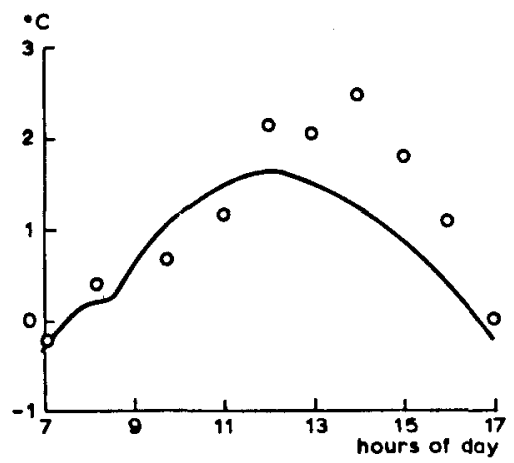

Fig. 8. Simulated (solid line) and measured leaf temperatures at $2 \mathrm{~m}$ height relative to the ambient air.

in Fig. 7 and may be caused by a beginning water stress that has not been taken into account in the simulator. The simulated soil evaporation is consistently too low although we made the surface wholly wet.

Temperatures are more sensitive to changes in diffusivity, which is difficult to measure, than are the fluxes of energy; hence temperatures are a sensitive test. First we shall present the simulated leaf temperatures at five heights by taping a thermocouple to a leaf at each height. The observed leaf temperatures at $2 \mathrm{~m}$ varied both markedly and regularly over the day, and the simulated leaf temperatures are compared with these observations (Fig. 8). The agreement is reassuring, depending as it does upon the rules for both stomatal resistances and boundary layer. Here also one can see some evidence of stomatal closure after noon in the excess of observed over simulated leaf temperatures.

Finally the observed and simulated air temperatures and vapour pressures within the canopy are compared in Fig. 9. The maximum temperatures observed by Brown are

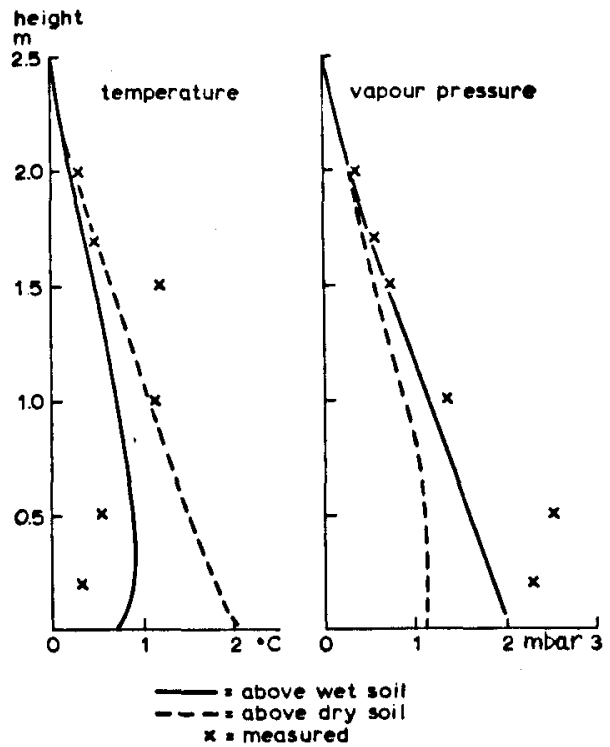

Fig. 9. Simulated and measured temperature and vapour pressure profiles of the air at $14 \mathrm{~h} 00$ above wet soil and above dry soil. 
higher in the canopy than we have simulated. Also the measured vapour pressures are higher than the simulated. The deviations are never larger than $0.7^{\circ} \mathrm{C}$ or 1 mbar.

In the introduction we promised to apply the simulator to wholly dry as well as moist soils. Wholly dry only refers to the condition of the surface; under a dry layer of a few $\mathrm{mm}$ the rest of the soil may be just as wet as before. Therefore we do not change the thermal properties but only the condition of the surface. Evaporation from the dry soil was computed in the same way as from a wet soil except it was opposed by a very large resistance. That is we made $\mathrm{q}_{\mathrm{n}-1}$ very large instead of zero. As soon as condensation occurs, however, this pseudo-stomatal resistance of the soil surface became zero. The same rule was applied to the stomatal resistances of the leaves. To account for this change these resistances were made zero whenever the evaporation or transpiration in the corresponding stratum was negative during the preceding time step. As soon as it turned positive the resistance got the normal value again; that is we did not wait till all dew was evaporated. It is within the capability of our model to keep track of a layer of dew by means of an integral for each stratum separately.

With the large $\mathrm{q}_{\mathrm{n}-1}$ and otherwise the same specifications as for wet soil we simulated two days for the dry soil. The main difference between the two soils appears to be the equilibrium soil temperature. Whereas in the wet soil the mean soil temperature arrives at $14.5^{\circ} \mathrm{C}$, the mean temperature becomes as high as $25^{\circ} \mathrm{C}$ in the dry soil. This must be due to the absence of latent heat loss. The daily course of the stimulated $G$ in the dry soil is also shown in Fig. 5. The day peak is higher and not so wide in the dry as in the moist soil.

The influence of soil moisture on the air temperature and humidity is presented in Fig. 9. As one would expect, the air becomes dryer and hotter above the dry than above the moist soil. During the night, the dew formation on the leaves will be less above a dry soil. In Fig. 10 the period of dew formation for both circumstances has been given in the different strata. Especially for the lower strata dew formation is governed by soil wetness. This agrees with Monteith's observations that often dew is distillated soil moisture rather than advected moisture of the air (Monteith, 1957). It

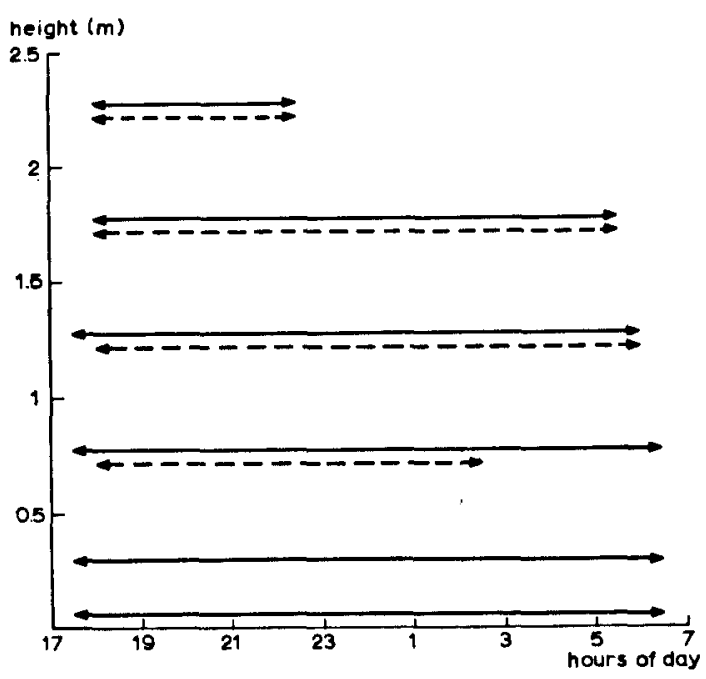

Fig. 10. Influence of soil wetness on the period of dew formation for different heights in the canopy. The solid line is the wet soil simulation, the dashed one the dry soil simulation. 
should be noted that only the duration of dew formation, not of wet leaves is given; the latter will be longer. The transpiration of the canopy is hardly affected by soil wetness and it increases only a few percent. The total evapotranspiration, of course, is reduced considerably because the soil no longer contributes to the evaporation.

\section{Discussion}

On the preceding pages we have presented and tested a method for simulating the microclimate, which is rarely observed but important to plants and their pests, from a specification of the foliage and the soil and observations of bef macroclimate above the canopy. Since this method may have some practical utility, it is well to itemize the parameters required for the calculation and the parameters that are calculated.

The foliage characteristics that must be known are:

a. Leaf area index and leaf area distribution with height;

b. Average leaf dimension for the calculation of the boundary layer;

c. Dependence of stomatal resistance on absorbed light, and where water stress will develop, also the dependency on the relative water content of the leaves. In our case it was not important but it is possible to keep track of the water content of the leaves in an integral and let the stomatal resistance depend on it. It is also possible to account for an adjustment time of the stomatal aperture by means of a simple integral statement. We did not do it because the radiation level was changing slowly and the stomatal opening could be considered as adjusted at any time. It may be useful to remark that the requirement of thermal equilibrium which is basic for out method does not mean that necessarily the stomatal aperture should be in equilibrium!

d. Extinction coefficent for visible radiation, short wave radiation and net radiation; e. Coefficient of extinction with relative depth for wind and diffusivity. Just as in radiation this can be considered as a foliage property.

The soil characteristics that must be known are:

a. Initial water content and temperature. Water is more important than temperature. The correct temperaure profile will be established after a day if calculation is begun at the average daily temperature, but the water content is liable to change in one way. The specification can be very rough, $5 \%$ accuracy is enough;

b. Hydraulic and thermal properties. If one knows the type and composition of the soil they can be calculated or taken from tabulated data;

c. The wetness of the surface. This is, of course, closely related to the initial water content;

d. Average clod dimension for the calculation of the boundary layer. The macroclimatic observations are mostly conventional ones: temperature, humidity, and wind at the top of the canopy. The other observations must be radiation and diffusivity. Although these two are not routinely observed, they can be fairly called part of the specification of the macroclimate.

The product of the simulator is manifold. It calculates the foliage temperature and transpiration, the air temperature and humidity within the canopy, the evaporation from the soil and the flux of heat into the soil, and finally the temperature of the soil. The changes in soil moisture caused by roots are not simulated as yet; only the evaporation from the surface has been calculated.

The practical utility of the simulator depends upon the realism of the calculations and the availability of the required specifications. The realism has been demonstrated 
within the preceding pages, and here we only investigate the availability of specifications. The distribution of the leaf area seems elementary and must always be available before calculations begin. The extinction coefficients for radiation and ventilation require elaborate and expensive observations, but considerable experience has been accumulated concerning them, e.g. Brown and Covey (1966).

Similarly the soil hydraulic and thermal properties are not easily observed, but the calculator can turn to the literature with some confidence as we did.

The macroclimatic wind, temperature and humidity are easily obtained. Where radiation data are not available, they must be estimated from time and cloudiness, as it has often been done in other calculations of evaporation. Diffusivity affects evaporation modestly, but when the temperatures profile is needed, diffusivity must be measured or estimated from a correlation between wind and radiation on the one hand, and diffusivity on the other.

The specifications that have not been obtained easily are those at the boundary between the air and soil. Although reasonable calculations can be made with the sort of values that we have used in or calculations, we must mention what is needed. First, measurements of diffusivity have ended, so far as we know, well above the soil. Thus the transition between turbulent air in the lower canopy and the still air of the (laminar) layer above the soil and around the lower stems is largely unknown. It is unimportant for the total evaporation from a succulent vegetation, but it is crucial for our understanding of evaporation from and warming of the soil. The boundary layer over the soil is also a region of ignorance. The final, obvious lacuna is the specification of the humidity at the soil surface, or, in other words, the resistance of the soil to vapour. This last bit of ignorance has restricted our simulations to either wet or dry soil, and it must be removed before simulation can be continued through the important drying of the surface.

\section{List of symbols}

\begin{tabular}{|c|c|c|}
\hline B & average dimension of a clod of soil & m \\
\hline $\mathrm{C}_{\mathrm{s}}$ & volumetric heat capacity of the soil & $\mathrm{J} \mathrm{m}^{-3}{ }^{\circ} \mathrm{C}-1$ \\
\hline $\mathrm{C}_{\mathrm{a}}$ & volumetric heat capacity of the air & $\mathrm{J} \mathrm{m}^{-3}{ }^{\circ} \mathrm{C}-1$ \\
\hline $\mathrm{D}_{\mathrm{a}}$ & diffusivity for heat in the air & $\mathrm{m}^{2} \mathrm{~s}^{-1}$ \\
\hline $\mathrm{D}_{\mathrm{s}}$ & diffusivity for water in the soil & $\mathrm{m}^{2} \mathrm{~s}-1$ \\
\hline e & vapour pressure of the air & mbar \\
\hline $\mathrm{e}_{\mathrm{sa}}$ & saturated vapour pressure at air temperature & mbar \\
\hline $\mathbf{F}$ & area of leaves per volume of air & $\mathrm{m}^{2} \mathrm{~m}^{-3}$ \\
\hline $\mathbf{G}$ & soil surface heat flux & $J \mathrm{~m}^{-2} \mathrm{~s}^{-1}$ \\
\hline $\mathbf{H}$ & sensible heat loss per stratum & $\mathrm{J} \mathrm{m}^{-2} \mathrm{~s}^{-1}$ \\
\hline $\mathrm{h}$ & sensible heat loss per leaf area & $J \mathrm{~m}^{-2} \mathrm{~s}^{-1}$ \\
\hline i & number of stratum & - \\
\hline $\mathbf{K}$ & hydraulic conductivity of the soil & $\mathrm{m} \mathrm{s}^{-1}$ \\
\hline $\mathbf{L}$ & thickness of the boundary layer & $\mathrm{m}$ \\
\hline $\mathbf{n}$ & total number of strata in the canopy & 一 \\
\hline Q & resistance between strata for latent heat & $\mathrm{s} \mathrm{m}-1$ \\
\hline q & resistance between leaf and ambient for latent heat per stratum & $\mathbf{s} \mathrm{m}^{-1}$ \\
\hline $\mathbf{R}$ & resistance between strata for sensible heat & $\mathbf{s} \mathrm{m}^{-1}$ \\
\hline $\mathrm{r}$ & resistance between leaf and ambient air for sensible heat per stratum & $\mathbf{s} \mathrm{m}^{-1}$ \\
\hline $\mathbf{r}_{\mathrm{a}}$ & the same but per leaf area & $s m^{-1}$ \\
\hline $\mathbf{r}_{\mathrm{s}}$ & stomatal resistance per leaf area & $\mathbf{s} \mathbf{m}^{-1}$ \\
\hline
\end{tabular}


absorbed total radiation per stratum absorbed total radaition per leaf area temperature of air or soil windspeed latent heat loss per stratum latent heat loss per leaf area relative volumetric water content of the soil relative volumetric solid content of the soil vertical dimension psychrometric constant first derivative of saturated vapour pressure at air temperature vapour pressure within the leaf leaf temperature conductivity for heat of the soil kinematic viscosity of the air energy flux in upward direction
$J \mathrm{~m}-2 \mathrm{~s}-1$

$\mathrm{J} \mathrm{m}^{-2} \mathrm{~s}^{-1}$

${ }^{\circ} \mathrm{C}$

$\mathrm{m} \mathrm{s}-1$

J $\mathrm{m}-2 \mathrm{~s}-1$

$\mathrm{J} m-2 \mathrm{~s}-1$

-

$\mathrm{m}$

mbar ${ }^{\circ} \mathrm{C}-1$

mbar ${ }^{\circ} \mathrm{C}-1$

mbar

${ }^{\circ} \mathrm{C}$

$\mathrm{J} \mathrm{m}^{-1}{ }^{\circ} \mathrm{C}-1$

$\mathrm{m}^{2} \mathrm{~s}^{-1}$

J $\mathrm{m}^{-2} \mathrm{~s}^{-1}$

\section{References}

Bresler, E. et al., 1970. Infiltration from a trickle source. Hebrew University, Jerusalem.

Brown, K. W., 1964. Vertical fluxes within the vegetative canopy of a cornfield. U. S. Department of Agriculture and Cornell University, Ithaca, N.Y., Interim Report 64-1.

Brown, K. W. \& W. Covey, 1966. The energy budget evaluation of the micrometeorological transfer processes within a cornfield. Agric. Met. 3: 73-96.

Keulen; H. van \& C. G. E. M. van Beek, 1971. Water movement in layered soils - A simulation model. Net'?, J, agric. Sci. 19: 138-153.

McAdams, W. H., 1954. Heat trahsmission. McGraw-Hill, New York.

Monsi, M. \& T. Saeki, 1953. Ueber den Lichtfaktor in den Pflanzengesellschaft und seine Bedeutung für die Stoffproduktion. Jap. J. Bot. 14: 22-52.

Monteith, J. L., 1957. Dew, Q. Jl. met. Soc. 83: 322-341.

Parlange, J. Y., P. E. Waggoner \& G. H. Heichel, 1971. Boundary layer resistance and temperature distribution on still and flapping leaves. Pl. Physiol. 48: 437-442.

Penning de Vries, F. W. T., 1972. A model for simulating transpiration of leaves with special attention to stomatal functioning. $J$. appl. Ecol. 9: 57-78.

Philip, J. R., 1964. Sources and transfer process in the air layers occupied by vegetation. J. appl. Met. 3: $390-395$.

Waggoner, P. E., G. M. Furnival \& W. E. Reifsnyder, 1969. Simulation of the microclimate in a forest. Forest Sci. 15: $37-45$.

Wierenga, P. J. \& C. T. de Wit, 1970. Simulation of heat transfer in soils. Proc. Soil Sci. Soc. Am. 34: $845-848$.

Wijk, W. R. van, 1963. Physics of plant environment. North-Holland Publ. Co., Amsterdam. 